\title{
Factors influencing turnover intention among primary care doctors: a cross- sectional study in Chongqing, China
}

Tong Wen ${ }^{1,2,3}$, Yan Zhang ${ }^{1,2,3^{*}}$, Xue Wang ${ }^{1,2,3}$ and Guo Tang ${ }^{1,2,3}$

\begin{abstract}
Background: The intention to leave a job, known as turnover intention, among primary care doctors has a significant impact on primary health care service delivery. We investigated primary care doctors' turnover intention and analysed associated factors involved in primary health facilities in Chongqing, China.

Methods: A total of 440 doctors were interviewed, they were selected using a multi-stage stratified random sampling method. The survey instrument was a self-administered questionnaire which assessed socio-demographic and workrelated characteristics, job satisfaction and turnover intention. The data were analysed using $x^{2}$ test, one-way analysis of variance, exploratory factor analysis and linear regression analysis.

Results: Our study found that $42.3 \%$ of the primary care doctors we sampled in Chongqing, China, intended to resign. Location, age, job title, doctor's position level, work pressure and job satisfaction were associated with turnover intention. Job satisfaction included both employment-related job satisfaction (including "your chance of promotion", "your rate of pay" and two other items) and satisfaction with the job itself (including "the freedom to choose your own method of working", "your job safety" and two other items).

Conclusions: Improving job satisfaction, in terms of salary, promotion and job safety, is crucial for reducing turnover intention among primary care doctors. Therefore, we suggest that the government increase its financial investment in primary care facilities, especially in less-developed areas, and reform incentive mechanisms to improve the job satisfaction of primary care doctors. The government should consider policies such as establishing a social pension programme for village-level doctors and providing more opportunities for job promotion among primary care doctors, especially township-level doctors. Attention should also be paid to the impact of rapid urbanization, which could lead to increased workload or increased opportunities for career development, thus affecting primary care doctors' turnover intention.
\end{abstract}

Keywords: Turnover intention, Job satisfaction, Doctor, Primary health care, China

\section{Background}

Primary health care (PHC) is pivotal now more than ever [1]. The demand for PHC is expected to increase considerably due to an ageing population with more chronic diseases [2]. However, primary care facilities are facing significant labour shortages worldwide [3]. According to the Association of American Medical

\footnotetext{
* Correspondence: camudzy@163.com

${ }^{1}$ School of Public Health and Management, Chongqing Medical University, Chongqing 400016, China

${ }^{2}$ Research Center for Medicine and Social Development, Chongqing Medical University, Chongqing 400016, China

Full list of author information is available at the end of the article
}

Colleges (AAMC), the USA will face a shortage of between 7300 and 43100 primary care physicians by 2030 [4]. Few young doctors are willing to devote themselves to primary health care, and many of those doctors already in practice are leaving [2]. Therefore, greater emphasis should be placed on the retention of primary care doctors.

According to the theory of planned behaviour, behavioural intention is a good predictor of actual behaviour [5]. At present, turnover intention is believed to be a more revealing figure than the turnover rate because intention is the antecedent of resignation, and it has a 
better predictive ability $[6,7]$. Turnover intention is used to measure people's intention to resign from their current job and look for another job, and follow through on resigning [8]. Hom and Griffeth describe turnover intention as the relative strength of an individual's desire to voluntary withdrawal from an organization [9]. Intention is the reason, and turnover is the result. The intention to resign leads to job searching behaviour, and when an alternative job presents itself, turnover occurs [10]. Steel and Ovalle reported a correlation coefficient of 0.50 between turnover intention and actual turnover after reviewing a significant number of studies [11]. A longitudinal study reported that family physicians in England with a strong intention to resign had 4.48 times the probability $(\mathrm{OR}=4.48,95 \% \mathrm{CI}: 2.32-8.66, p<0.001)$ of actual resignation after 5 years compared with physicians with no turnover intention [12]. These results indicate that higher turnover intention indeed predicted a greater likelihood of actually leaving. Accordingly, placing a focus on factors that affect the intention to resign rather than addressing the turnover itself would be more efficient $[13,14]$.

There are no formally validated scales that measure turnover intention [15]. Most researchers have adopted single-item scales to measure turnover intention $[16$, 17]. However, this kind of measurement had obvious metric limitations [18]. Michaels et al. developed a turnover intention scale [10], and $\mathrm{Li}$ et al. revised the scale for use in China, where it was used to measure nurses' turnover intention. This revised scale, consisting of six items, included three aspects of turnover intention and surmised that an individual's turnover intention depended on his or her intention to resign, motivation to search for a new job and the probability of finding another job $[19,20]$.

Factors associated with turnover intention, such as job satisfaction, working conditions and individual characteristics, have been reported in the literature [21]. Job satisfaction encompasses an employee's level of satisfaction with the job and work environment [22]. Some researchers noted that job satisfaction was the most important antecedent variable for directly anticipating turnover intention [23, 24]. However, it is important to know which particular aspects of job satisfaction affects turnover intention. One study explored how satisfaction with the job rewards affected employees' turnover intention. The researchers found that turnover intention was affected by satisfaction with financial rewards, material rewards and psychological rewards. Furthermore, along with job satisfaction, individual characteristics, such as gender, age and family responsibilities, also play an essential role in turnover intention [25].

In China, two types of doctors deliver primary care services: village-level doctors and township-level doctors.
Village-level doctors are not considered government employees and only receive limited compensation from the government, and do not receive insurance coverage, while township-level doctors receive fixed wages and employee insurance [26]. In addition, working conditions for village-level doctors are poorer than those of township-level doctors. In China, the proportion of the PHC health workers in the health workforce decreased by $5.9 \%$ between 2009 and 2014 [27]. The number of PHC doctors falls short of the 1.25 million primary care doctors needed to ensure that China meets the goal established by the National Medical and Health Service System Planning (2015-2020), which requires that "number of primary care doctors per thousand population is 3.5 and above by 2020 ".

In 2009, the Chinese government launched the Health System Reform Plan to strengthen PHC to improve the delivery of basic medical care and public health services [28]. However, the investment in the delivery side of $\mathrm{PHC}$ is insufficient, which may affect the retention of workforce [29]. A study from central China showed that income satisfaction and organizational policies affected the turnover intention of village-level doctors [30]. Another study in the capital of China noted that improving the retirement pensions and incomes of rural doctors helped increase human resources for PHC [26].

There are scarce data regarding turnover intention among PHC doctors in western China, which is the poorest regions and which has far less health resources than the rest of China. In this study, we conducted a sampling study of primary care doctors in Chongqing (southwestern China) with the aim of evaluating their level of turnover intention and exploring its associated factors. We hypothesized that (1) turnover intention was associated with job satisfaction and affected by some aspects of job satisfaction and (2) socio-demographic characteristics played a role in turnover intention.

\section{Methods \\ Sampling and data collection}

This study was conducted in Chongqing, which is located in southwestern China. Chongqing is one of the four municipalities under direct control of the central government of China, which occupies 82.4 thousand square kilometres with a population of 30.07 million (according to 2015 figures). In 2013, the government divided Chongqing into five areas based on their available socio-economic resources: the metropolitan core area, the metropolitan extension area, the newly developed urban area, the ecological conservation area and the environmental protection area.

Chongqing has become well developed in recent years and has received considerable attention from the central government of China; however, the primary health care 
situation is troubling. In 2014, the number of doctors per 1000 residents was only 1.72, the 10th lowest among the 12 provinces of western China. According to the Health Statistical Yearbook for Chongqing, the number of primary care doctors in township health centres decreased by $10.92 \%$, and the number of health care workers in village clinics decreased by $10.58 \%$ between 2011 and 2016 [31]. The disparity in human resources among the different areas is also evident. In 2014, the metropolitan area had the highest doctor-patient ratio (2.78 doctors per thousand population), while the environmental protection area had the lowest (1.45 doctors per thousand population). To some extent, we may view Chongqing as being representative of China as a whole, since it includes both urban areas and remote poor villages. For example, the per capita gross domestic product (GDP) of Yuzhong district, which is located in the metropolitan core area, was more than 30000 dollars, while the per capita GDP in Wuxi (a county in the ecological conservation area) was only 3014 dollars in 2015 [31]. A similar pattern of disparities in health care workers and economic development can be seen throughout the country. This study provides a chance to understand the problems that exist in the primary care system from the perspective of those that deliver healthcare services.

In this study, we combined the metropolitan core area and the metropolitan extension area into one metropolitan area, which allowed us to obtain a sample from each of the four areas with a complete administrative regional boundary descripted earlier. A multi-stage stratified random sampling method was used to collect a sample of 350 township-level doctors from 32 township health centres or community health centres, and 90 villagelevel doctors from 64 village clinics or community health stations. All the participating doctors gave their informed consent before completing the questionnaire.

\section{Measurement instruments}

A self-administered questionnaire consisting of four parts was used for this quantitative survey; it included a cover letter outlining the objective of the study and the instructions on how to complete the survey.

- Part 1 included basic socio-demographic characteristics: gender, age, education background, and medical practice type, job title and location of job within the four previously described areas.

- Part 2 composed of work-related characteristics including the organization, amount of pressure at work, years of work, work hours per week, number of patients seen per week, annual income and training.

- In part 3, job satisfaction was measured using a 16-item questionnaire produced by Warr et al., we included an additional item to measure job satisfaction associated with doctor-patient relations ("relationship with patients") [32]. Thus, we developed a 17-item questionnaire using a 7-point scale with responses ranging from 1 = "very dissatisfied" to 7 = "very satisfied". Higher scores indicated a higher level of satisfaction on each item. The Cronbach's alpha was excellent (0.96).

- Part 4 comprised multiple choice questions about reasons for resigning, as well as the six-item turnover intention scale (TIS-6), developed by Michaels et al. and revised by Li et al. for the Chinese population, which was used to measure the doctors' intention to resign [10, 20]. Items included "Have you considered resigning from your current job?", "Do you want to find another, similar job?" and four other items. A 4-point scale was adopted for each item with responses ranging from 1 = "never" to 4 = "always". A high score indicated stronger turnover intention, and the total score of all six items was calculated to assess the overall turnover intention (" $\leq 15$ " comprised the "low" group and " $>15$ " comprised the "high" group). Items 1 and 6 were related to turnover intention I, indicating the intent to resign from the current job (TIS-I); items 2 and 3 were related to turnover intention II, indicating the motivation to search for other jobs (TIS-II); and items 4 and 5 were related to turnover intention III, indicating the probability of obtaining a new job (TIS-III). The Cronbach's alpha of the TIS- 6 was 0.75 .

\section{Data analysis}

Through double entry and validation in EpiData3.1, collected data were analysed using SAS 9.4 (SAS Institute, Inc., NC). Means and standard deviations (SD) were calculated for quantitative data, while percentages were calculated for qualitative data. Descriptive statistical analyses were conducted for socio-demographic variables, work-related characteristics, job satisfaction and turnover intention scores. $\chi^{2}$ test was used to compare the different reasons given for resigning from the current job by doctor's position level (i.e. township or village level), age and location areas. One-way analysis of variance (ANOVA) was used to explore the impact of sociodemographic variables and work-related characteristics on doctors' turnover intention. Exploratory factor analyses (EFA) was conducted for the job satisfaction scale using the principal component extraction method with an orthomax rotation to determine whether unique patterns of items existed. The principles including "the eigenvalue for each factor $\geq 1$ ", "cumulative variance explained by factors is above $75 \%$ " and scree plots were all taken into consideration when determining the common 
factors. The explanation of practical significance for each underlying factor was based on the factor loading value. A value of 0.5 is considered acceptable. Regression estimation was conducted to evaluate the factor score for each observation [33, 34]. In model I, significant sociodemographic variables in one-way ANOVA and overall job satisfaction were included, and in model II, the factors extracted by exploratory factor analysis replaced overall job satisfaction. The level of $p<0.05$ was considered statistically significant in all tests.

\section{Results}

\section{Socio-demographic and work-related characteristics of the study sample}

A total of 440 primary care doctors participated in this survey, and 433 validated questionnaires were collected. There were 345 township-level doctors and 88 villagelevel doctors. Of these participants, $68.4 \%$ were male. The mean age was $40.9( \pm 9.93)$ age ranged from 21 to $72,22.6 \%$ of the doctors had bachelor's degrees or higher, and $27.0 \%$ had a mid-level or higher job title. The mean number of hours worked per week was $54.7 \mathrm{~h}$ (median $=50 \mathrm{~h}$ ), and the mean number of patients seen per week was $62.9($ median $=50)$. Among the sample, $63.9 \%$ had an annual income of 20,000-39,999 RMB (2929-5858 US dollars), and $73.9 \%$ of the primary care doctors had participated in vocational training during the last 3 years (Table 1 ).

\section{Turnover intention and related reasons among primary care doctors}

The mean total score of turnover intention among the participants in this survey was 14.23 ranged from 6 to 24 . The probability of obtaining a new job (TIS-III) had the highest score (mean score $=5.67$ ranged from 2 to 8 ), followed by motivation to search for other jobs (TISII; mean score $=4.31$ ranged from 2 to 8 ); intention to resign from the current job (TIS-I) had the lowest score (mean score $=4.25$ ranged from 2 to 8 ). Based on the criterion of scores ">15" as "high", $42.3 \%$ of the doctors had high turnover intention. The main reasons for resigning from the current job included "low salary" (73.7\%), "high work risk" (39.3\%), "work pressure" (37.2\%) and "seeking better career development" (32.1\%) (Fig. 1). About half (50.7\%) of the village-level doctors regarded high work risk as the main reason to resign, which was higher than township-level doctors (36.7\%), while more township-level doctors (35.4\%) than village-level doctors (18.2\%) gave "seeking better career development" as the main reason to resign (Fig. 2). Eighty one point nine percent of primary care doctors aged from 30 to 39 years thought that salary was the main reason to resign, and more doctors under the age of $30(40.7 \%)$ thought that current job prospects was the main reason to resign (Fig. 3). Figure 4 shows that more primary care doctors working in the environmental protection area considered low salary $(90.5 \%)$, poor working conditions (47.6\%) and current job prospects (36.2\%) as the main reasons to resign, while more primary care doctors in the newly developed urban area considered work pressure (52.7\%), high work risk (51.4\%) and seeking better career development $(48.7 \%)$ as the main reasons to resign. All the differences mentioned above were statistically significant $(p<0.05)$.

\section{Job satisfaction among primary care doctors and exploratory factor analysis of the job satisfaction scale} The mean score of overall job satisfaction of the primary care doctors was 4.89 ranged from 1 to 7 . The doctors were most dissatisfied with "your rate of pay" (score = $3.61 \pm 1.66$ ranged from 1 to 7 ), followed by the chance of job promotion (score $=4.22 \pm 1.54$ ranged from 1 to 7). The top four common factors on satisfaction were extracted from the job satisfaction scale with a cumulative variance of $78.7 \%$. The communality variance for each item was greater than $70 \%$, which means that these four factors reflect the most information for each item. According to the 0.5 principle, factor 1 included "your immediate boss" and four other items, reflecting satisfaction with organizational administration. Factor 2 included "your chance of promotion", "your rate of pay", and two other items, reflecting employment-related job satisfaction. Factor 3 included "the freedom to choose your own method of working", "your job safety" and two other items, reflecting satisfaction with the job itself. Factor 4 included "your fellow workers" and two other items, indicating relationship-related satisfaction. The factor loading distribution map is shown in Table 2.

\section{Predictors of turnover intention among primary care doctors}

One-way ANOVA assesses the association between the turnover intention and socio-demographic and workingrelated variables (Table 1 ), and these variables with statistical significance are included in the regression analysis.

Controlling for other variables, doctor's position level was an important predictor of turnover intention $(b=-0.174$ in model I; $b=-0.138$ in model II). Township-level doctors had higher turnover intention than village-level doctors. Similarly, location areas were another predictor of turnover intention. Compared with the metropolitan area, doctors in the other three areas showed higher turnover intention, especially in the newly developed urban area $(b=0.264, p<0.0001)$ and the environmental protection area $(b=0.263, p<0.0001)$. Younger doctors had higher turnover intention; doctors with higher job titles had higher turnover intention; and higher work pressure predicted higher turnover 
Table 1 Descriptive data for the primary care doctors who participated in this study $(n=433)$

\begin{tabular}{|c|c|c|c|c|}
\hline $\begin{array}{l}\text { Socio-demographic } \\
\text { and work-related factors }\end{array}$ & Groups & $\begin{array}{l}\text { Number of doctors } \\
n(\%)\end{array}$ & $\begin{array}{l}\text { Turnover intention } \\
(\overline{\boldsymbol{x}} \pm \boldsymbol{\delta})\end{array}$ & $p$ value \\
\hline \multirow[t]{2}{*}{ Doctor's position level } & Township level & $345(79.7)$ & $14.64 \pm 3.43$ & $<0.0001$ \\
\hline & Village level & $88(20.3)$ & $12.61 \pm 4.17$ & \\
\hline \multirow[t]{4}{*}{ Location areas } & Metropolitan area & $101(23.3)$ & $12.54 \pm 3.31$ & $<0.0001$ \\
\hline & Newly developed urban area & $106(24.5)$ & $14.67 \pm 3.46$ & \\
\hline & Ecological conservation area & $121(27.9)$ & $14.14 \pm 3.72$ & \\
\hline & Environmental protection area & $105(24.3)$ & $15.50 \pm 3.62$ & \\
\hline \multirow[t]{3}{*}{ Medical practice type } & Traditional Chinese medicine & $59(13.4)$ & $13.42 \pm 3.82$ & 0.0498 \\
\hline & Western medicine & 196(45.3) & $14.65 \pm 3.56$ & \\
\hline & Integrated traditional Chinese and Western medicine & 178(41.1) & $14.02 \pm 3.72$ & \\
\hline \multirow[t]{2}{*}{ Gender } & Male & 296(68.4) & $14.34 \pm 3.84$ & 0.3548 \\
\hline & Female & 137(31.6) & $13.99 \pm 3.32$ & \\
\hline \multirow[t]{3}{*}{ Age } & $<30$ & $54(12.5)$ & $14.17 \pm 3.32$ & 0.0025 \\
\hline & $30-39$ & 145(33.5) & $15.06 \pm 3.49$ & \\
\hline & $>=40$ & 234(54.0) & $13.72 \pm 3.80$ & \\
\hline \multirow[t]{3}{*}{ Education } & Bachelor's degree or higher & $98(22.6)$ & $14.69 \pm 3.36$ & 0.0009 \\
\hline & College degree & 202(46.7) & $14.65 \pm 3.62$ & \\
\hline & High school graduation (secondary technical school) or below & 133(30.7) & $13.24 \pm 3.84$ & \\
\hline \multirow[t]{3}{*}{ Job title } & None & $61(14.1)$ & $13.13 \pm 4.06$ & 0.0177 \\
\hline & Entry level & 255(58.9) & $14.23 \pm 3.84$ & \\
\hline & Middle level or above & $117(27.0)$ & $14.78 \pm 2.96$ & \\
\hline \multirow[t]{3}{*}{ Years of working } & $<10$ & $84(19.4)$ & $14.24 \pm 3.43$ & 0.0139 \\
\hline & $10-19$ & 159(36.8) & $14.84 \pm 3.47$ & \\
\hline & $>=20$ & 189(43.8) & $13.68 \pm 3.89$ & \\
\hline \multirow[t]{3}{*}{ Annual income } & $<20000$ & $66(15.3)$ & $14.26 \pm 4.12$ & 0.9854 \\
\hline & $20000-39999$ & 276(63.9) & $14.22 \pm 3.66$ & \\
\hline & $>=40000$ & $90(20.8)$ & $14.30 \pm 3.33$ & \\
\hline \multirow[t]{2}{*}{ Working time per week } & $<50$ & 164(37.9) & $13.37 \pm 3.47$ & 0.0001 \\
\hline & $>=50$ & $269(62.1)$ & $14.75 \pm 3.71$ & \\
\hline \multirow[t]{2}{*}{ Number of patients per week } & $<50$ & 214(49.4) & $14.07 \pm 3.85$ & 0.3692 \\
\hline & $>=50$ & 219(50.6) & $14.38 \pm 3.51$ & \\
\hline \multirow[t]{2}{*}{ Training during the last 3 years } & Yes & $320(73.9)$ & $14.08 \pm 3.75$ & 0.1502 \\
\hline & No & $113(26.1)$ & $14.65 \pm 3.45$ & \\
\hline
\end{tabular}

Note: figures in italics mean $p<0.05$, indicating that the results of one-way ANOVA showed statistical significance

intention. In model I, overall job satisfaction was negatively associated with turnover intention $(b=-0.180, p$ $<0.0001)$. When four job satisfaction factors replaced overall job satisfaction, the adjusted $R^{2}$ changed from 0.257 to 0.303 . Factor 2 (employment-related job satisfaction) and factor 3 (satisfaction with the job itself) significantly predicted turnover intention among primary care doctors. Items such as "your chance of promotion (factor loading $=0.830$ )", "your rate of pay (factor loading $=0.790)$ ", "the freedom to choose your own method of working (factor loading $=0.724$ )" and "your job safety (factor loading $=0.643$ )" had high factor loading (Tables 2 and 3).

\section{Discussion}

Strengthening PHC has high priority in China's new medical system reform. Reducing primary care doctors' turnover intention and improving the stability of human resources for PHC is crucial to the success of the reforms. We found that $42.3 \%$ of primary care doctors in the study had high turnover intention, which is higher than the rate of community health practitioners in the 


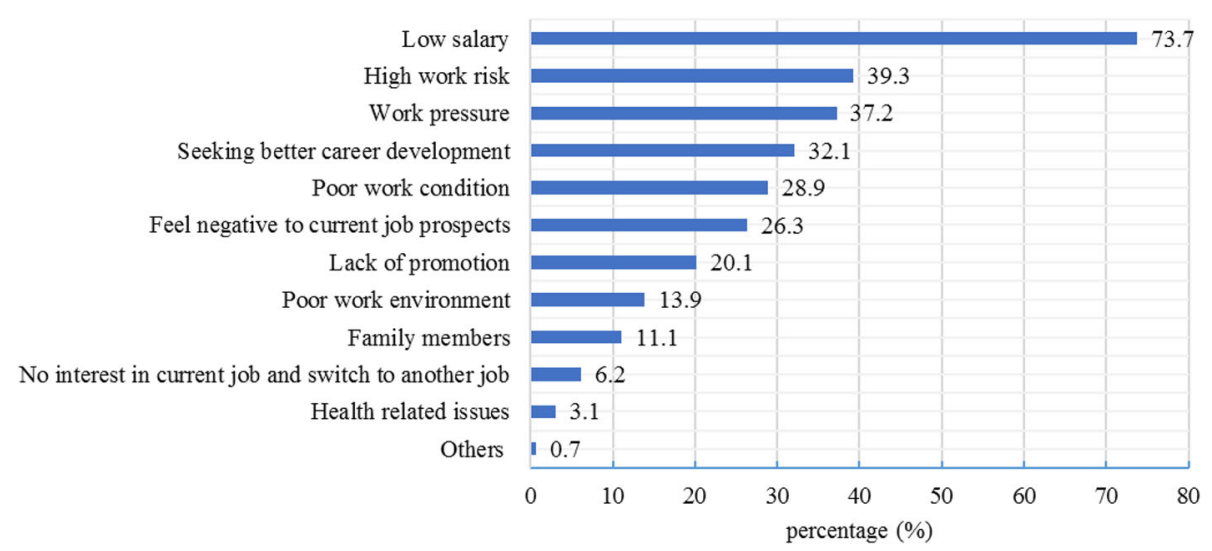

Fig. 1 Main reasons to quit current job

five other provinces in China (38.7\%) [35] and higher than village doctors in Xiangyang, a city in Hubei province of China (36.8\%) [30], while a study from England showed that only $11.8 \%$ of primary care doctors had high turnover intention [12]. In addition, the score of turnover intention III (the probability of obtaining a new job) was the highest compared with the two other dimensions, probably due to the increase in available jobs as a result of the new medical reform. While the new medical reform aims to improve PHC, it unfortunately creates a brain drain as doctors move away from primary care practice [36]. The reform of public hospitals at the county level has expanded the scale of medical institutions, and a policy that encourages private investment in the medical field has improved the medical market share of private hospitals. Senior medical facilities, including county public hospitals and private hospitals, are willing to recruit experienced doctors from primary care settings [36]. In this survey, we also found socio-

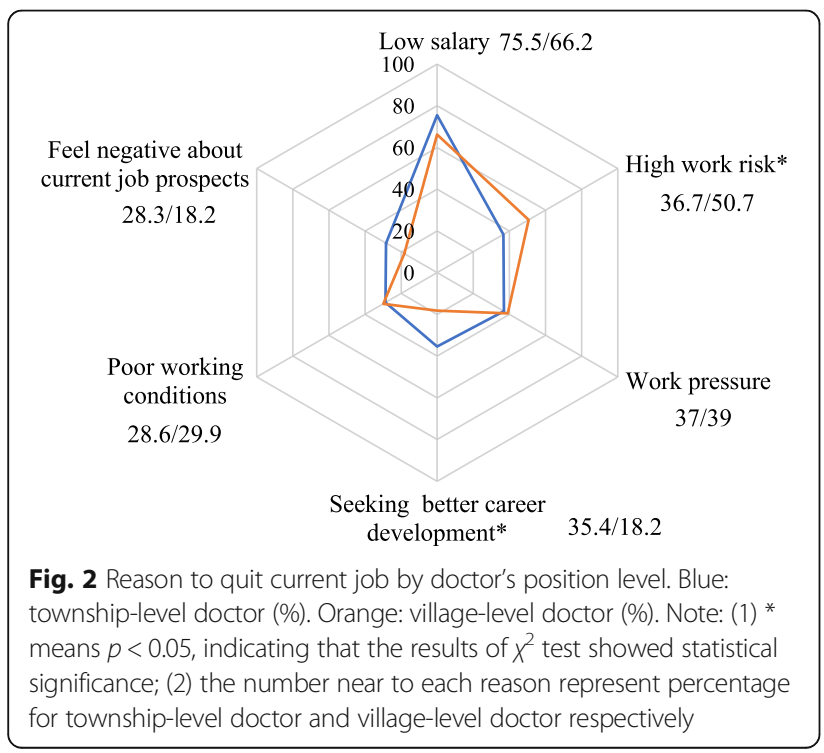

demographic variables such as working at the township level, having a higher job title or being between 30 and 39 years of age, were associated with higher turnover intention, probably due to their greater experience and professional ability, and higher probability of changing a job.

In this study, we found a negative correlation between job satisfaction and turnover intention among primary care doctors, which is in line with similar reports $[16$, $17,30,35]$. Using exploratory factor analysis, we integrated the 17 items of the job satisfaction scale into four core factors, of which employment-related job satisfaction and satisfaction with the job itself, including chance of promotion, your rate of pay and the other six items, were the two that significantly predicted turnover intention. Those items were correlated and interactional affecting turnover intention.

Of the eight items of job satisfaction, chance of promotion and your rate of pay had the highest factor loading, as knowledgeable doctors, especially young doctors, pay more attention to career development when choosing a job, including the chance of promotion and training opportunities [37]. Compared with large public hospitals, the working conditions of primary care facilities are poorer, with fewer training opportunities and limited chances for job promotion [36, 38]. In this study, doctors under 30 years old were more likely to think that seeking better career development opportunities (46.3\% of doctors) and feeling negative about prospects in their current positions ( $40.7 \%$ of doctors) were the main reasons for resigning from a job. Both these rates were lower than $30 \%$ in doctors older than 30 years of age. Meng et al. also reported that primary care doctors transferred to higher-level medical institutions because of limited opportunities for job promotion in primary care facilities [39]. Less than $25 \%$ of the doctors who participated in this study had a bachelor's degree or higher, and over $70 \%$ of them had only an entry level job 


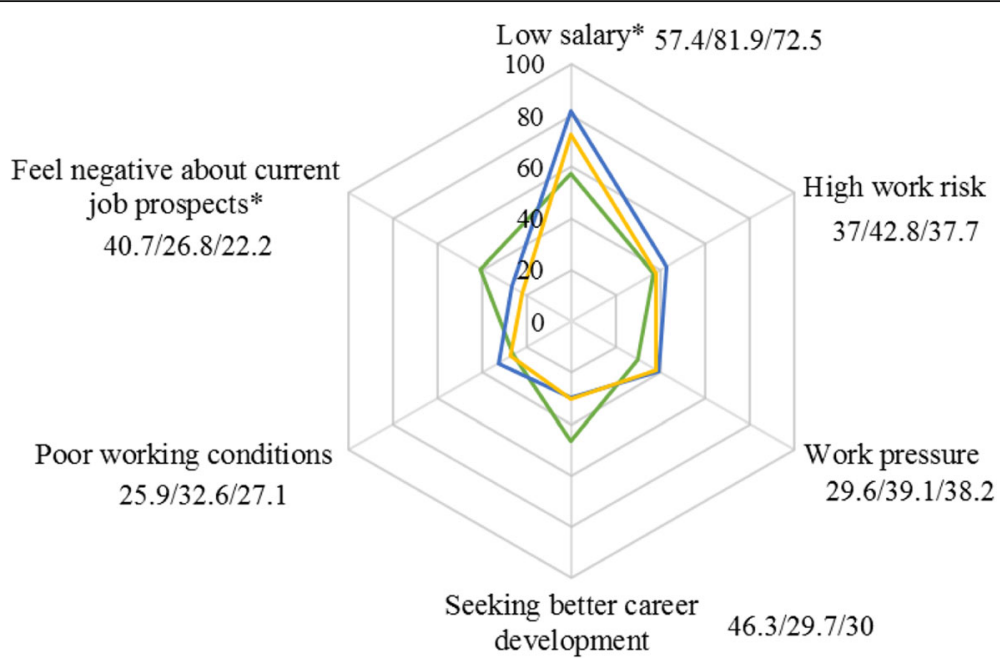

Fig. 3 Reason to quit current job by age. Green: Age < 30 (\%). Blue: Age 30-39 (\%). Yellow: Age $>=40$ (\%). Note: (1) * means $p<0.05$, indicating that the results of $x^{2}$ test showed statistical significance; (2) the number near to each reason represent percentage for primary care doctors age under 30 years old, age between 30 and 39 years old and age 40 years old or older respectively

title or lower. These results reflect both the shortage of high-level doctors in PHC and the difficulty of professional advancement, both of which are due to inadequate training mechanisms and job title evaluation mechanisms. Although primary care doctors are willing to participate in training or on-the-job education to improve their professional abilities, training is expensive and income during training is not always guaranteed. Therefore, the training is mostly short-term or a mere formality, and this may be the reason no association between training and turnover intention was found in our

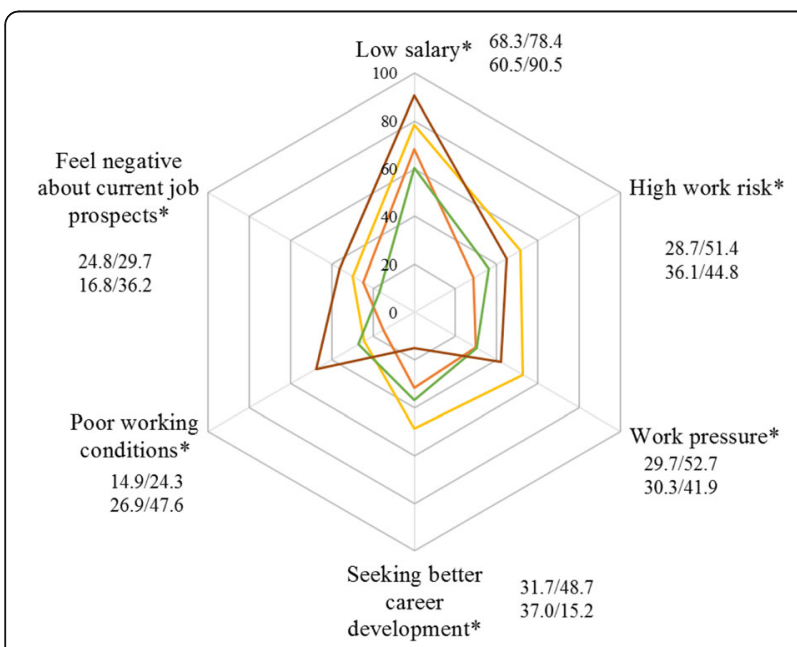

Fig. 4 Reason to quit current job by location areas. Orange: metropolitan area (\%). Yellow: newly developed urban area (\%). Green: ecological conservation area (\%). Brown: environment protection area (\%). Note: (1)* means $p<0.05$, indicating that the results of $x^{2}$ test showed statistical significance; (2) the number near to each reason represent percentage for metropolitan area, newly developed urban area, ecological conservation area and environment protection area respectively study, which was different from the findings of other studies [35, 40-42]. Due to the lack of effective training, it is difficult for primary care doctors to improve their professional abilities. In short, few opportunities and strict evaluations lead to limited job promotion for doctors in primary care facilities [36].

Low salary, which is disproportionate to the high workload and work pressure, is one of the main reasons for high turnover intention. After the Chinese government launched the Health System Reform Plan in 2009, the content of basic public health services was expanded, and primary care doctors are now required to deliver both medical services and public health services [28]. If the PHC workforce is not significantly increased, this demand can only be met by increasing the workload of primary care doctors, which will undoubtedly increase both the physical and psychological pressure they experience [29]. We found that $62.1 \%$ of the doctors in this survey worked more than $50 \mathrm{~h}$ per week. The reform of human resources for primary care facilities is still underway, and the mechanism for incentive and compensation are still imperfect. PHC doctors' income has been affected by the Chinese government's a zero-mark-up policy on drug sales. For one thing, the profits from drug sales have disappeared; for another thing, patients may go to other medical institutions because of the limitation of the varieties of basic drugs available at primary care facilities; however, the financial support is not subsidized timely. In one study, $74.8 \%$ of village-level doctors reported dissatisfaction with their financial compensation [30]. Another study reported that primary care doctors thought that their salaries were disproportionate to their amount of work [43]. This kind of inequality causes job dissatisfaction, which affects turnover intention [33]. 
Table 2 Score and exploratory factor analysis results for the job satisfaction scale $(n=433)$

\begin{tabular}{|c|c|c|c|c|c|c|}
\hline Items & $\begin{array}{l}\text { Score } \\
(\overline{\boldsymbol{x}} \pm \boldsymbol{\delta})\end{array}$ & Factor 1 & Factor 2 & Factor 3 & Factor 4 & Communalities \\
\hline Your immediate boss & $5.38 \pm 1.38$ & 0.819 & & & & 0.839 \\
\hline Industrial relationship between management and workers in your firm & $5.03 \pm 1.31$ & 0.704 & & & & 0.828 \\
\hline The attention paid to suggestions you make & $4.60 \pm 1.30$ & 0.659 & & & & 0.805 \\
\hline The way your firm is managed & $4.69 \pm 1.40$ & 0.637 & & & & 0.748 \\
\hline The amount of responsibility you are given & $4.86 \pm 1.33$ & 0.635 & & & & 0.746 \\
\hline Your chance of promotion & $4.22 \pm 1.54$ & & 0.830 & & & 0.821 \\
\hline Your rate of pay & $3.61 \pm 1.66$ & & 0.790 & & & 0.774 \\
\hline Your opportunity to use your abilities & $4.56 \pm 1.35$ & & 0.624 & & & 0.749 \\
\hline Your hours of work & $4.46 \pm 1.44$ & & 0.555 & & & 0.725 \\
\hline The freedom to choose your own method of working & $4.38 \pm 1.46$ & & & 0.724 & & 0.798 \\
\hline Your job safety & $4.88 \pm 1.32$ & & & 0.643 & & 0.788 \\
\hline The amount of variety in your job & $4.45 \pm 1.33$ & & & 0.634 & & 0.805 \\
\hline The physical working conditions & $4.40 \pm 1.44$ & & & 0.571 & & 0.798 \\
\hline Your fellow workers & $5.12 \pm 1.25$ & & & & 0.716 & 0.822 \\
\hline The recognition you get for good work & $4.82 \pm 1.25$ & & & & 0.681 & 0.813 \\
\hline Relationship with patients & $5.09 \pm 1.19$ & & & & 0.550 & 0.732 \\
\hline $\begin{array}{l}\text { Now, taking everything into consideration, } \\
\text { how do you feel about your job as a whole? }\end{array}$ & $4.89 \pm 1.29$ & & & & & \\
\hline Eigenvalue & & 9.998 & 1.162 & 0.779 & 0.652 & \\
\hline Cumulative variance explained by factors (\%) & & 0.625 & 0.698 & 0.746 & 0.787 & \\
\hline
\end{tabular}

Table 3 Multivariate linear stepwise regression analysis of factors related to turnover intention

\begin{tabular}{|c|c|c|c|c|}
\hline \multirow[t]{2}{*}{ Factors } & \multicolumn{2}{|l|}{ Model I } & \multicolumn{2}{|l|}{ Model II } \\
\hline & $b$ & p & $b$ & $p$ \\
\hline \multicolumn{5}{|l|}{ Age, years } \\
\hline$<30$ vs $>=40$ & 0.074 & 0.1151 & 0.107 & 0.0228 \\
\hline $30-39$ vs $>=40$ & 0.179 & 0.0001 & 0.208 & $<0.0001$ \\
\hline \multicolumn{5}{|l|}{ Location areas } \\
\hline Newly developed urban area vs metropolitan area & 0.264 & $<0.0001$ & 0.248 & $<0.0001$ \\
\hline Ecological conservation area vs metropolitan area & 0.146 & 0.0078 & 0.116 & 0.0342 \\
\hline Environment protection area vs metropolitan area & 0.263 & $<0.0001$ & 0.222 & $<0.0001$ \\
\hline \multicolumn{5}{|l|}{ Doctor's position level } \\
\hline Village-level doctors vs township-level doctors & -0.174 & 0.0001 & -0.138 & 0.0031 \\
\hline Work pressure & 0.241 & $<0.0001$ & 0.196 & $<0.0001$ \\
\hline Job title & - & - & 0.109 & 0.0176 \\
\hline Overall job satisfaction & -0.180 & $<0.0001$ & - & - \\
\hline Factor 2 & - & - & -0.297 & $<0.0001$ \\
\hline Factor 3 & - & - & -0.142 & 0.0015 \\
\hline$R^{2}$ & 0.271 & & 0.320 & \\
\hline Adjusted $R^{2}$ & 0.257 & & 0.303 & \\
\hline
\end{tabular}


Among primary care doctors between 30 and 39 years old, and who are the primary breadwinners in their households, $81.9 \%$ thought the main reason to resign was low salary, compared with only $57.4 \%$ of those under the age of 30 .

Job safety also has a high factor loading. Low job safety predicts high turnover intention. At present, the medical environment is deteriorating, and medical disputes are continuing to increase, posing threats to doctors' personal safety [44]. Due to the low education level and limited professional ability of primary care doctors, the feeling of job unsafe is even more serious, especially among village-level doctors. One explanation is that most village-level doctors are private practitioners, whose job safety is not safeguarded by large institutional and rules and regulations [45]. In addition, they do not have fixed wages and the same social welfare benefits as township-level doctors or even village teachers, causing village-level doctors to feel unsafe and unsatisfied with their job. [46]. We found that $50.7 \%$ of the village-level doctors thought that high risk to their safety at work was the main reason to resign from a job, compared with $36.7 \%$ of the township-level doctors.

In addition to the chance of promotion, your rate of pay and job safety, as mentioned above, the freedom to choose their own method of working, physical working conditions and the amount of variety in their job also affected turnover intention. Wu et al. reported the deteriorating doctor-patient relationships had an impact on doctors' job satisfaction [44]; however, in our study, the primary care doctors were satisfied with their doctorpatient relationships, and there was no association found between doctor-patient relationship and turnover intention. In Chinese town and village culture, the relationship between primary care doctors and patients is closer than a typical doctor-patient one which promotes deep mutual trust and communication due to their shared family, communities, lifestyles and beliefs [47].

Location areas also matter significantly in explaining turnover intention. Doctors in the environmental protection area had the highest turnover intention. This area is least-developed with inferior primary care facilities, and most of the doctors working there reported that low salary (90.5\%) and poor working conditions (47.6\%) were the main reasons for turnover intention, these rates were much higher than that of other areas. Doctors in the newly developed urban area also had high turnover intention, possibly because of the rapid urbanization process in this area. On the one hand, fast urbanization results in a series of social problems (e.g. larger population, heavy traffic, increasing air pollution), which may have an impact on people's health. For another thing, the growth rate of investment in human resources for health lags considerably behind population growth and urbanization progress [48], which can result in additional workload and pressure for primary care doctors, thus leading to high turnover intention. In the newly developed urban area, primary care doctors thought that work pressure (52.7\%) and high work risk (51.4\%) were the main reasons for turnover intention, which was higher than the other three area locations. On the other hand, urbanization also provides primary care doctors with more opportunities to seek better career development, and $48.7 \%$ of the doctors in the newly developed urban area reported seeking better career development as the main reason for turnover intention.

The Chinese government has taken action to address the shortage of health care workers for PHC, especially in rural areas. For example, in 2010, the Chinese government launched a "rural-oriented medical student cultivation programme" [49]. However, the effect of this policy intervention was not ideal. Several studies have shown that $35.28 \%$ of enrolled students wanted to default after graduation, and less than $5 \%$ of students were willing to continue to deliver $\mathrm{PHC}$ services after the expiration of their agreed mandatory time [50-52]. Therefore, the key to reducing the turnover intention of primary doctors and solving the shortage of human resources for PHC is to improve the working and living conditions of primary care doctors and increase their chance of promotion.

\section{Limitations}

The first limitation of this study is the representativeness of the sample. Our research sample was relatively small, which may have an impact on statistical reference and test power. However, we collected the sample using a strict sampling method, and the participants were welldistributed throughout Chongqing, which can guarantee the sample's representativeness. Second, there may be information bias resulting from social proof or "correctness" since we used a questionnaire in this quantitative research; however, the bias has been greatly reduced by making the participants anonymous, a well-designed questionnaire and good communication between investigators and participating doctors. Third, this crosssectional study limited the range of information we could gather. Therefore, in future research, we will expand the sample size and conduct a longitudinal study to evaluate turnover intention and the relationship between intent to resign and turnover.

\section{Conclusions}

Primary care doctors play a vital role in driving the performance of health care systems at the grassroots level. Our study showed that the turnover intention of primary care doctors in Chongqing, China, is high and is affected by different aspects of job satisfaction. Considering that improving job satisfaction, in terms of salary, promotion 
and job safety, is crucial for reducing turnover intention among primary care doctors, we suggest that the government increase its financial investment in primary care facilities, especially in less-developed areas, and reform incentive mechanisms to improve the job satisfaction of primary care doctors. The government should consider policies such as establishing a social pension programme and legal protection system for village-level doctors to reduce their vulnerability to medical risks, improving training mechanisms and establishing a job title evaluation system to increase the chance of job promotion among primary care doctors, especially young doctors and township-level doctors. Attention should also be paid to the impact of rapid urbanization, which could lead to increased workload or increased opportunities for career development, thus affecting primary care doctors' turnover intention. The adoption of these recommendations may help to accelerate the development of PHC in Chongqing, China.

\section{Abbreviations \\ ANOVA: Analysis of variance; $b$ : Standardized regression coefficient; EFA: Exploratory factor analysis; GDP: Gross domestic product; PHC: Primary health care; $p$ value: Level of significance; SD: Standard deviation; TIS- 6: Turnover intention scale; TIS-I: Turnover intention I; TIS-II: Turnover intention II; TIS-III: Turnover intention III; $x^{2}$ : Chi-square test}

\section{Acknowledgements}

The funding agents for this study played no role in the study's design, data collection, data analyses, the decision to publish or in the preparation of the final manuscript. The authors would like to express their gratitude to every primary care facility and participant in this survey.

\section{Funding}

The project was funded by the Western Area Health Initiative (WAHI) (WPCHN1408195), Chongqing Social Science Planning Project (2013QNL50) and Medical Research Program of Chongqing City Health and Family Planning Committee (2013-2-153).

\section{Availability of data and materials}

The data that support the findings of this study are available from the corresponding author upon reasonable request.

\section{Authors' contributions}

YZ, TW, XW and GT designed the survey; XW, TW and GT conducted the survey and collected the data; TW and YZ organized and analysed the data; TW and YZ wrote the paper; XW and GT provided feedback to the drafts of the manuscript. All authors reviewed the consent of the manuscript and approved the final version of the manuscript

\section{Ethics approval and consent to participate}

We conducted the research following the Declaration of Helsinki, and the protocol was approved by the Ethics Committee of Chongqing Medical University (Ref. 2014047). All participating primary care doctors signed the informed consent before completing the questionnaire.

\section{Consent for publication}

Not applicable.

\section{Competing interests}

The authors declare that they have no competing interests.

\section{Publisher's Note}

Springer Nature remains neutral with regard to jurisdictional claims in published maps and institutional affiliations.

\section{Author details}

${ }^{1}$ School of Public Health and Management, Chongqing Medical University, Chongqing 400016, China. ${ }^{2}$ Research Center for Medicine and Social Development, Chongqing Medical University, Chongqing 400016, China. ${ }^{3}$ Innovation Center for Social Risk Governance in Health, Chongqing Medical University, Chongqing 400016, China.

Received: 31 March 2017 Accepted: 5 February 2018

Published online: 13 February 2018

\section{References}

1. World Health Organization. The World Health Report 2008 - Primary Health Care (Now More Than Ever). 2008. Available on: http://www.who.int/whr/2008/en/.

2. American College of Physicians. How Is a Shortage of Primary Care Physicians Affecting the Quality and Cost of Medical Care?. Philadelphia: American College of Physicians; 2008: White Paper. (Available from American College of Physicians, $190 \mathrm{~N}$. Independence Mall West, Philadelphia, PA 19106.)

3. World Health Organization. Global health workforce shortage to reach 12.9 million in coming decades, 2013. Available on: http://www.who.int/ mediacentre/news/releases/2013/health-workforce-shortage/en/.

4. IHS Markit. The complexities of physician supply and demand 2017 update: projections from 2015 to 2030. Washington: Association of American Medical Colleges; 2017. Available on: https://aamc-black.global.ssl.fastly.net/production/ media/filer_public/c9/db/c9dbe9de-aabf-457f-aee7-1d3d554ff281/aamc_ projections_update_2017_final___june_12.pdf. Accessed 11 Mar 2017.

5. Ajzen I. The theory of planned behaviour. Organ Behav Hum Decis Process. 1991;50(2):179-211.

6. Zhang $Y$, Feng $X$. The relationship between job satisfaction, burnout, and turnover intention among physicians from urban state-owned medical institutions in Hubei, China: a cross-sectional study. BMC Health Serv Res. 2011;11:235.

7. Brewer CS, Kovner CT, Greene W, Cheng Y. Predictors of RNs' intent to work and work decisions 1 year later in a U.S. national sample. Int J Nurs Stud. 2009;46(7):940-56.

8. Bedeian AG, Armenakis AA. A path-analytic study of the consequences of role conflict and ambiguity. Acad Manag J. 1981;24(2):417-24.

9. Hom PW, Griffeth RW. A structural equation modelling test of a turnover theory: cross sectional and longitudinal analysis. J Appl Psychol. 1991;76:350-66.

10. Michaels CE, Speetor PE. Causes of employee turnover: a test of the mobley, griffeth, hand, and meglion model. J Applied Psychol. 1982;67(1):55-9.

11. Steel R, Ovalle N. A review and meta-analysis of research on the relationship between behavioural intentions and employee turnover. J Appl Psychol. 1984;69(4):673-86

12. Hann M, Reeves D, Sibbald B. Relationships between job satisfaction, intentions to leave family practice and actually leaving among family physicians in England. Eur J Pub Health. 2011;21(4):499-503.

13. Jacobs E, Roodt G. Organisational culture of hospitals to predict turnover intentions of professional nurses. Health SA Gesondheid. 2008:13(1):63-78.

14. Oluwafemi OJ. Predictors of turnover intention among employees in Nigeria's oil industry. Organ Mark Emerg Econ. 2013:4(98):42-63.

15. Sager JK, Griffeth RW, Hom PW. A comparison of structural models representing turnover cognitions. J Vocational Behav. 1998;53(2):254-73.

16. Bonenberger $\mathrm{M}$, Aikins $\mathrm{M}$, Akweongo $\mathrm{P}$, Wyss $\mathrm{K}$. The effects of health worker motivation and job satisfaction on turnover intention in Ghana: a crosssectional study. Hum Resour Health. 2014;12:43.

17. Ali Jadoo SA, Aljunid SM, Dastan I, Tawfeeq RS, Mustaf MA, Ganasegeran K, AlDubai SA. Job satisfaction and turnover intention among Iraqi doctors-a descriptive cross-sectional multicentre study. Hum Resour Health. 2015;13:21.

18. Martin A, Roodt G. Perceptions of organisational commitment, job satisfaction and turnover intentions in a post merger tertiary institution. SA J Ind Psychol. 2008;34(1):23-31.

19. Zhang L, Huang L, Liu M, Yan H, Li X. Nurse-physician collaboration impacts job satisfaction and turnover among nurses: a hospital-based cross-sectional study in Beijing. Int J Nurs Pract. 2016;22(3):284-90.

20. Dong-rong $L$, Jing-yuan Li. A study on the relationships among role conflict, organizational structure. Master's thesis, National Chiao Tung University, Taiwan, 2000. (In Chinese).

21. Degen C, Li J, Angerer P. Physicians' intention to leave direct patient care: an integrative review. Hum Resour Health. 2015;13(1):74.

22. Smith PC, Kendall LM, Hulin CL. The measurement of satisfaction in work and retirement. Chicago: Rand McNally; 1969. 
23. Ye R. Analysis on the causes of employee turnover in state-owned enterprises. PhD thesis, Southwest Jiaotong University, Chengdu, China, 2005. (In Chinese).

24. Van Dick R, Christ O, Stellmacher J, Wagner U, Ahlswede O, Grubba C, Hauptmeier M, Hohfeld C, Moltzen K, Tissington PA. Should I stay or should I go? Explaining turnover intention with organizational identification and job satisfaction. Br J Manag. 2004;4:351-60.

25. De Gieter S, Hofmans J. How reward satisfaction affects employees' turnover intentions and performance: an individual differences approach. Hum Resour Manag J. 2015:25(2):200-16.

26. Wang J, Su J, Zuo H, Jia M, Zeng Z. What interventions do rural doctors think will increase recruitment in rural areas: a survey of 2778 health workers in Beijing. Hum Resour Health. 2013;11:40.

27. Qin JM, Zhang LF, Lin CM, et al. Scale and allocation of human resources in primary health care system in China after new medical reform. Chin Gen Pract. 2016;19(4):378-82. (In Chinese)

28. Chen Z. Launch of the health-care reform plan in China. Lancet. 2009; 373(9672):1322-4.

29. Cao H, Yin W, Ma M, Tang M, Tan H, Chen Z, Qin X. Study on the impact of essential medicine system on doctors' job satisfaction in township health center. Chin Hosp. 2017:21(5):37-40. (In Chinese)

30. Fang $P$, Liu X, Huang L, Zhang X, Fang Z. Factors that influence the turnover intention of Chinese village doctors based on the investigation results of Xiangyang City in Hubei Province. Int J Equity Health. 2014;13:84

31. Chongqing Health and Family Planning Commission.Chongqing Health Statistics Yearbook. 2010-2016. Available on: http://tj.cqshic.com/. Accessed 11 Mar 2017.

32. Warr P, Cook J, Wall T. Scales for the measurement of some work attitudes and aspects of psychological well-being. J Occup Psychol. 1979;52:129-48.

33. Fogarty L, Kim YM, Juon HS, Tappis H, Noh JW, Zainullah P, Rozario A. Job satisfaction and retention of health-care providers in Afghanistan and Malawi. Hum Resour Health. 2014;12:11.

34. Masum AK, Azad MA, Hoque KE, Beh LS, Wanke P, Arslan O. Job satisfaction and intention to quit: an empirical analysis of nurses in Turkey. Peer J. 2016; 4:e1896.

35. Sun $Y$, Luo Z, Fang P. Factors influencing the turnover intention of Chinese community health service workers based on the investigation results of five provinces. J Community Health. 2013;38(6):1058-66.

36. Tian M, Zhang XJ, Zhu K. The status quo, problems and countermeasures of human resource turnover in township hospitals of China. Chin J Health Policy. 2016;9(6):32-7. https://doi.org/10.3969/j.issn.1674-2982.2016.06.007 . (In Chinese)

37. Song K, Scott A, Sivey P, Meng Q. Improving Chinese primary care providers' recruitment and retention: a discrete choice experiment. Health Policy Plan. 2015;30(1):68-77.

38. Li X, Yuan T, Xin X, et al. Investigation and factor analysis of hunting intention for rural grassroots of medical students in Gansu Province. Chin J Health Pol. 2016; 9(9):71-7. https://doi.org/10.3969/j.issn.1674-2982.2016.09.013 . (In Chinese)

39. Meng Q, Yuan J, Jing L, Zhang J. Mobility of primary health care workers in China. Hum Resour Health. 2009;7:24.

40. WHO Guidelines Approved by the Guidelines Review Committee. In increasing access to health workers in remote and rural areas through improved retention: global policy recommendations, World Health Organization. Geneva: World Health Organization; 2010.

41. Mathauer I, Imhoff I. Health worker motivation in Africa: the role of nonfinancial incentives and human resource management tools. Hum Resour Health. 2006:4:24.

42. Patterson M, Rick J, Wood S, Carroll C, Balain S, Booth A. Systematic review of the links between human resource management practices and performance. Health Technol Assess. 2010;14(51):1-334, iv. https://doi.org/ 10.3310/hta14510.

43. Min Z, Jin M. Study on the relationship between medical service charge and medical staff's labor value in public hospitals in China. Price Theory Pract. 2009;1:35-6.

44. Wu D, Wang Y, Lam KF, Hesketh T. Health system reforms, violence against doctors and job satisfaction in the medical profession: a cross-sectional survey in Zhejiang Province, Eastern China. BMJ Open. 2014;4(12):e006431.

45. Zhou XD, Li L, Hesketh T. Health system reform in rural China: voices of healthworkers and service-users. Soc Sci Med. 2014;117:134-41.

46. Ding Y, Smith HJ, Fei Y, Xu B, Nie S, Yan W, Diwan VK, Sauerborn R, Dong H. Factors influencing the provision of public health services by village doctors in Hubei and Jiangxi provinces, China. Bull World Health Organ. 2013;91(1):64-9.
47. Zhang $X$, Wang $X$, Peng $Y$, et al. Present situation and influencing factor of the doctor-patient trust in rural area from the villager's perspective. Chin Med Ethics. 2015;28(3):349-52. (In Chinese)

48. Qin X, Li L, Hsieh C. Too few doctors or too low wages? Labor supply of health care professionals in China. China Econ Rev. 2013;24(1):150-64.

49. National Development and Reform Commission. Notice on the Rural Oriented Medical Student Cultivation Programme. 2010. http://www.gov. cn/zwgk/2010-06/08/content_1623025.htm. Accessed 15 Oct 2017.

50. Wang Y, Zhang SQ, Liu BZ, et al. The relevant factors influencing directional medical students serve for community. Chin Gen Pract. 2014;17(25):29963000. https://doi.org/10.3969/j.issn.1007-9572.2014.25.023. (In Chinese)

51. Fan WY, Wang $X$, et al. Empirical research on the status of specialty cognition of rural-oriented tuition-waived medical students and its influence factors. Chin Health Serv Manage. 2014;1:45-7. (In Chinese)

52. Hu D, Chen CK, Zhang C, et al. Policy implementation of targeted admission medical education program in rural areas. Chin J Health Pol. 2016;9(9):60-4. https://doi.org/10.3969/j.issn.1674-2982.2016.09.011. (In Chinese)

\section{Submit your next manuscript to BioMed Central and we will help you at every step:}

- We accept pre-submission inquiries

- Our selector tool helps you to find the most relevant journal

- We provide round the clock customer support

- Convenient online submission

- Thorough peer review

- Inclusion in PubMed and all major indexing services

- Maximum visibility for your research

Submit your manuscript at www.biomedcentral.com/submit
Biomed Central 